\title{
Estimating the environmental benefits of ride-sharing: a case study of Dublin
}

\section{Brian Caulfield*}

\author{
Department of Civil, Structural and Environmental Engineering, Trinity College \\ Dublin, Dublin 2, Ireland
}

\begin{abstract}
Ride-sharing has often been cited as a successful method to reduce congestion and green house gas emissions. This paper examines the patterns of ride-sharing, in Dublin, and estimates the environmental benefits of ride-sharing both in terms of reductions in emissions and the total vehicle kilometres travelled. Data from the 2006 Census of Ireland is used in this paper to examine the travel patterns of those that ride-share. Ride-sharing in Dublin currently accounts for $4 \%$ of the total morning peak commute trips. The COPERT4 model is used in this paper to estimate the $\mathrm{CO}_{2}$ emissions saved by ride-sharing.
\end{abstract}

Keywords: ride-share; sustainable transport

\section{Introduction}

Between 1996 and 2006 the population of Ireland has grown by $17 \%$ to just under 4.2 million people. Private car ownership has increased by $38 \%$ in the same period (Department of Transport, 2009). This rapid growth has resulted in chronic congestion in urban areas and escalating green house gas emissions (GHG). $\mathrm{CO}_{2}$ emissions from transport have grown by $88 \%$ in this 10 year period to $13.7 \mathrm{Mt}$ of $\mathrm{CO}_{2}$ emissions perannum. Energy use in the transport sector was over $99 \%$ dependent on oil products in 2005 (SEI, 2006). These trends are not unique to Ireland; such patterns have been replicated in many other countries.

In an attempt to reduce emissions and congestion, the Irish Government has launched a plan to promote sustainable transport policies. It is proposed that this plan will work in conjunction with the planned investment in capital projects. This sustainable transport plan will encourage behavioural change, and promote soft measures. This paper examines one such soft measure, ride-sharing. Ride-sharing (or carpooling) is an arrangement whereby two or more individuals travel in one vehicle from a given origin to a specific destination. The ride-sharing trips that are examined in this paper focus on weekday morning trips to work. Currently in Dublin, individuals that to ride-share do not have access to high occupancy vehicle lanes. These lanes are restricted to public transport vehicles.

\section{Ride-sharing}

Many countries see reducing transport emissions as one of their key targets for meeting national Kyoto reduction targets. However, meeting these targets will require an integrated package of behavioural policy measures to ensure travel is conducted in a

* Corresponding author. Tel +3531896 2534; fax: +35316773072

Email address: brian.caulfield@tcd.ie (B. Caulfield) 
more carbon efficient way (Hickman and Banister, 2007). One such method of carbon efficient travel is to ride-share. The promotion of ride-sharing in conjunction with other modes such as public transport is crucial to solving our oil dependence problems (Sovacool, 2007).

Ride-sharing has the potential to yield significant economic and environmental benefits. Reductions in journey time and vehicle kilometres travelled (VKT), shared fuel costs, and decreases in emission, can all be achieved from encouraging ride-sharing (Fellows and Pitfield, 2000). Jacobson and King (2009) examine the potential fuel savings in the United States if policy of ride-sharing were promoted. Authors found that if 1 in every 10 cars were to have more than one passenger, it could result in a saving of 5.4\% in annual fuel consumption. In 2005, the International Energy Agency (IEA) examined the potential benefits of promoting ride-sharing, in Organisation for Economic Cooperation and Development (OECD) countries. This study found that by adding one person to every commute trip, in each of the countries in the OECD, it would result in a saving of $7.7 \%$ on fuel consumption or 2,223 barrels of oil a day and reduce the total VKT by $12.5 \%$ (IEA, 2005). This report stresses it is essential that ridesharing lanes and priority parking measures are provided, to encourage ride-sharing. The provision of ride-share lanes is seen as essential for the promotion of this mode of transport. The benefits of reductions in VKT and improvements in air quality are cited as arguments for providing ride-share lanes in urban areas (Ungermah et al, 2007). A further policy tool which could be employed to promote ride-sharing is to use fiscal measures such as reducing fuel tax for those individuals that ride-share (Meyer, 1999, Rajan, 2006).

\section{Data and methodology}

\subsection{Data}

The Census data used in this paper was taken on the night of Sunday, $23^{\text {rd }}$ April 2006. 1.5 million homes in Ireland received the Census forms two weeks before the night of the $23^{\text {rd }}$ of April. The data analysed in this paper were taken from the place of work Census of anonymised records dataset (POWCAR) (CSO, 2007). The POWCAR dataset contains information on the regular work trips of $1,834,472$ individuals in Ireland.

Table 1 presents the modal split of the morning peak trips to work in Dublin. When completing the Census form individuals are asked to select the mode of transport they use to travel to work, school, or college. The Census form states 'tick one box only for the longest part, by distance, of your usual journey to work school or college' (CSO, 2006). The results show that $4 \%$ of respondents ride-share. The average distances travelled, the total kilometres travelled, and the times taken by each mode of transport are detailed in Table 2. Ride-sharers were found to travel on average of $9.75 \mathrm{~km}$; those that drive alone were shown to travel on average $11.24 \mathrm{~km}$ each day. As one would expect the average distance travelled for the slow modes was found to be considerably less than that of the mechanised modes. The results show that car and bus are responsible for the largest amount of VKT for trips to work each day in Dublin. Those that ride-share travel a total of $310,008 \mathrm{~km}$ per-day, for trips to work. 
Table 1

Mode split

\begin{tabular}{|c|c|c|}
\hline Mode of transport & $\mathbf{N}$ & $\%$ \\
\hline Walk & 70,080 & 13 \\
\hline Cycle & 20,602 & 4 \\
\hline Bus & 76,816 & 14 \\
\hline Rail & 39,534 & 7 \\
\hline Motorcycle & 6,607 & 1 \\
\hline Car-Driver & 260,754 & 49 \\
\hline Ride-share & 19,977 & 4 \\
\hline Lorry/van & 19,239 & 4 \\
\hline Other means & 1,028 & 0 \\
\hline Work from home & 8,218 & 2 \\
\hline NA & 9,364 & 2 \\
\hline Total & 532,219 & 100 \\
\hline
\end{tabular}

Table 2

Distance travelled and time taken

\begin{tabular}{l|rrrrr}
\hline $\begin{array}{l}\text { Mode of } \\
\text { transport }\end{array}$ & \multicolumn{3}{|c}{ Distance travelled in km } & \multicolumn{2}{c}{ Journey time in mins } \\
\cline { 2 - 6 } & Average & $\begin{array}{c}\text { Standard } \\
\text { deviation }\end{array}$ & $\begin{array}{c}\text { Total km travelled } \\
\text { (daily basis for a } \\
\text { return trip) }\end{array}$ & Average & $\begin{array}{c}\text { Standard } \\
\text { deviation }\end{array}$ \\
\hline Walk & 2.17 & 1.53 & 223,026 & 19 & 13 \\
Cycle & 5.48 & 3.88 & 199,487 & 22 & 12 \\
Bus & 9.51 & 7.29 & $1,145,350$ & 42 & 26 \\
Rail & 13.47 & 9.5 & 910,455 & 44 & 21 \\
Motorcycle & 10.84 & 8.1 & 127,052 & 25 & 14 \\
Car-Driver & 11.24 & 10.24 & $4,990,200$ & 31 & 21 \\
Ride-share & 9.75 & 9.7 & 310,008 & 28 & 20 \\
\hline
\end{tabular}

\subsection{Methodology}

A logistic regression analysis is applied in this study to examine the relationships between those individuals that ride-shared and those that did not. The reference category used in the logistic regression analysis was those respondents that ride-shared. The logistic regression analysis can be expressed as follows in equation [1]:

$\ln \left[\frac{p_{i}}{1-p_{i}}\right]=a+\sum b_{i} X_{i}+e$

where $p_{i}$ is the probability that the respondent ride-shared, $a$ is the intercept, $X_{i}$ and $b_{i}$ are explanatory variables and $e$ represents the error term. The results of the logistic regression analysis are presented in Table 3.

COPERT4 was used to calculate the $\mathrm{CO}_{2}$ emissions for each of the different scenarios considered in this paper (Gkatzoflias et al, 2007). COPERT4 is a computer model which estimates the emissions from road transport. COPERT4 is one of the most commonly used models in the European Union for estimating the emissions from road transport (Soylu, 2007). The details of the private fleet of vehicles used to estimate the savings in $\mathrm{CO}_{2}$ were taken from the government vehicle registration records (Department of the 
Environment, Heritage, and Local Government, 2005). Monthly average temperatures for 2006 were also inputted into the COPERT4 model.

\section{Results}

\subsection{Who are the individuals that are most likely to ride-share?}

The results of the logistic regression analysis are outlined in Table 3. The $p$-values estimated, demonstrate that each of the variables are significant. The negative coefficient estimated for the male variable, suggests that females are more likely to rideshare. Younger individuals were shown to be the most likely to ride-share, with those aged 35-44 the least likely.

As one might expect, couples were found to be more likely to ride-share. The results for the number of cars per-household shows that, households with just one car were found to be the most likely to ride-share. The coefficients that represent the occupation, demonstrate that those in management, higher and lower professionals and non-manual workers were all estimated to have negative coefficients. This result indicates that individuals employed in these professions were less likely to ride-share. Manual skilled, skilled, and un-skilled workers were all show to be more likely to rideshare. The final coefficients presented in Table 3 relate to the departure time. The results show that individuals that ride-share are most likely to depart between 7:01-7:30 and 7:31-8:00. It was not possible to examine household income in this study, as this attribute was not contained in the dataset released by the Central Statistics Office. 
Table 3

Logistic regression results

Variables

Estimate -Value

Intercept

$-1.825$

.011

Individual attributes

Gender

Male

$-0.532$

.000

Female

Age cohort

15-24

0.795

$-0.143$

.000

25-34

$-0.517$

.000

$35-44$

$-0.413$

$55-64$

$-0.402$

.000

65-74

.000

Household structure

Single

$-1.102$

Lone parent

$-0.273$

.000

Couple

0.137

.000

Other

Number of cars per-household

None

$-0.448$

.000

One car

0.073

.000

Two cars

$-1.037$

.000

Three cars

$-1.092$

.000

Four or more

Occupation

Employer and management

$-0.922$

.000

Higher professional

$-1.157$

.044

Lower professional

$-0.901$

.113

Non-manual

$-0.452$

.021

Manual skilled

0.143

.000

Semi-skilled

0.101

.047

Unskilled

0.461

.000

Own account worker

$-0.866$

.011

Farmer

$-1.051$

.000

Agricultural worker

0.352

.000

Others

Time of departure

Before 06:00

0.148

.000

06:31-07:00

0.370

.000

07:01-07:30

0.479

.078

07:31-08:00

0.518

.140

08:01-08:30

0.352

.020

08:31-09:00

0.299

.000

09:01-09:30

0.167

.000

After 09:30

0.270

.000

Not applicable

-2 log-likelihood at convergence

14947.217 $\mathrm{N}$ 


\subsection{Environmental benefits of ride-sharing}

The environmental benefits examined in this paper relate to reductions in $\mathrm{CO}_{2}$ emissions. The COPERT4 model was used to estimate the reductions in $\mathrm{CO}_{2}$ emissions. The savings in $\mathrm{CO}_{2}$ emissions and VKT presented in this section of the paper are assumed to occur as the ride-sharers, forgo driving to work. The reductions in $\mathrm{CO}_{2}$ emissions are given a monetary value in each of the scenarios modelled in this section. This monetary value was estimated using equation [2].

$$
V_{R}=\sum \Delta C O_{2}(c)
$$

where $\mathrm{V}_{\mathrm{R}}$ is the monetary value of the change in $\mathrm{CO}_{2}$ emissions and $\mathrm{c}$, is the value pergram of $\mathrm{CO}_{2}$. A value of $€ 0.00006$ per-gram of $\mathrm{CO}_{2}$, this is the value prescribed by the National Roads Authority of Ireland when placing a monetary value on $\mathrm{CO}_{2}$ emissions (NRA, 2005).

The three scenarios modelled are presented in Table 4. As shown in Table 2, ride-sharers were found to travel a total of $310,008 \mathrm{~km}$, each day in Dublin. The first scenario assumes a return trip, five days per-week, 44 weeks a year. The second scenario assumes the same as the first, but individuals are assumed to ride-share four days a week. The final scenario again assumes the same as the first, but individuals are assumed to ride-share three days a week.

The results for the first scenario show that annually 12,674 tonnes of $\mathrm{CO}_{2}$ emissions are saved by individuals ride-sharing. As the first scenario is based upon the findings taken from the Census data, it is fair to say that this $\mathrm{CO}_{2}$ emission saving was realised. The monetary value for this estimated saving on $\mathrm{CO}_{2}$ emissions was $€ 706,428$. Scenarios 2 and 3 demonstrate that if respondents were to ride-share 4 or 3 times a week, there would be a sizable annual saving in $\mathrm{CO}_{2}$ emissions. Each of the scenarios modelled in Table 4 show a considerable saving in the VKT on an annual basis.

Table 4

COPERT4 Results - Base scenarios

\begin{tabular}{l|rrr}
\hline Travel modelled & $\begin{array}{c}\text { Total vehicle km } \\
\text { saved (millions) }\end{array}$ & $\begin{array}{c}\mathbf{C O}_{2} \\
\text { (tonnes) }\end{array}$ & $\begin{array}{c}\text { Monetary } \\
\text { Value }\end{array}$ \\
\hline Scenario 1 - ride-sharing 5 days a week & 68.2 per annum & 12,674 & $€ 706,428$ \\
Scenario 2 - ride-sharing 4 days a week & 54.6 per annum & 10,139 & $€ 608,343$ \\
Scenario 3 - ride-sharing 3 days a week & 40.9 per annum & 7,604 & $€ 456,257$ \\
\hline
\end{tabular}

\section{Discussion and conclusions}

The general consensus from the literature is that a combination of approaches will be required to reduce $\mathrm{CO}_{2}$ emissions and promote sustainable transport. A number of policies need to be considered that both provide viable alternatives to driving and change individuals' behavioural habits by encouraging the use of sustainable transport options. As part of this policy mix the results of this paper make the case for supporting polices that promote ride-sharing, as it is shown to provide considerable benefits.

The characteristics of the individuals that currently ride-share in Dublin are examined in this paper using a logistic regression analysis. The results show that females and those in couples were most likely to ride-share. Occupation was found to 
significantly impact upon individual's decision to ride-share. The findings demonstrate that those in skilled or non-skilled and those in manual industries were found to be more likely to ride-share that those individuals employed as higher or lower professionals or those in management. Age was also found to be significant, with younger individuals shown to be the most likely to ride-share.

The results presented in this study demonstrate the benefits of ride-sharing, and the potential of this mode of transport for reducing $\mathrm{CO}_{2}$ emissions. Under the different scenarios examined, one can see that even if ride-sharing isn't the mode of transport that is used everyday when travelling to work, if it is used three or four days a week it can result in considerable benefits. These scenarios were analysed as permanent ridesharing arrangements are hard to maintain. The results of this study present a strong case for promoting ride-sharing and providing incentives such as ride-share lanes and financial incentives.

\section{Acknowledgement}

The author would like to thank the Central Statistics Office of Ireland for providing the POWCAR dataset.

\section{References}

Central Statistics Office. 2006. Census of Ireland Form. CSO, Dublin, Ireland.

Central Statistics Office. 2007. Census of population of Ireland 2006, Place of Work, Census of Anonymised Records (POWCAR) Users Guide. CSO, Dublin, Ireland.

Department of the Environment, Heritage and Local Government, 2004. Irish Bulletin of Vehicle and Driver Statistics 2003, Government Publications, Dublin.

Department of Transport. 2009. Smarter Travel - A sustainable transport future. Dublin, Ireland.

Fellows, N. T., Pitfield, D.E. 2000. An economic and operational evaluation of urban car-sharing. Transportation Research D 5, 1-10.

Gkatzoflias, D., Kouridis, C., Ntziachristos, L. 2007. COPERT 4: Computer programme to calculate emissions from road transport. European Environment Agency.

Hickman, R., Banister, D. 2007. Looking over the horizon: Transport and reduced $\mathrm{CO}_{2}$ emissions in the UL by 2030. Transport Policy 14, 377-387.

International Energy Agency. 2005. Saving oil in a hurry: measures for rapid demand restraint in transport. Draft Report, OECD, Paris, 2005

Jacobson, S. H., King, D.M. 2009. Fuel saving and ridesharing in the US: Motivations, limitations, and opportunities. Transportation Research Part D. 14, 14-21 
Meyer, M. D. 1999. Demand management as an element of transportation policy: using carrots and sticks to influence travel behaviour. Transportation Research A. 33, 575599.

NRA. 2005. Guidelines for cost benefit analysis, National Roads Authority, Ireland

Rajan, S.C. 2006. Climate change dilemma: technology, social change or both? An examination of long-term transport policies in the United States. Energy Policy 34, 664679.

Sustainable Energy Ireland. 2006. Energy in Transport: trends influencing factors 2006 Report, Sustainable Energy Ireland, Dublin Ireland.

Sovacool, B.K. 2007. Solving the oil independence problem: Is it possible? Energy Policy 35, 5505-5514.

Soylu, S. 2007. Estimation of Turkish road transport emissions. Energy Policy, 35, 4088-4094

Ungemah, D., Goodin, G., Dusza, C. 2007. Examining incentives and preferential treatment of carpools on managed lane facilities. Journal of Public Transportation, Vol. 10. No.4. 